\title{
Individualised risk communication of sediment-disaster evaluated using a psychological process model
}

\author{
A. Taniguchi ${ }^{1}$, S. Fujii ${ }^{2}$, N. Osanai ${ }^{3}$ \& H. Ito ${ }^{4}$ \\ ${ }^{I}$ Department of Risk Engineering, University of Tsukuba, Japan \\ ${ }^{2}$ Department of Urban Management, Kyoto University, Japan \\ ${ }^{3}$ Erosion and Sediment Control Division, \\ Japanese Ministry of Land, Infrastructure, and Transport, \\ National Institute for Land and Infrastructure, Japan \\ ${ }^{4}$ Faculty of Policy Studies, Iwate Prefectural University, Japan
}

\begin{abstract}
This study developed a non-emergency risk-communication program focusing on sediment disasters. The program, which targeted local residents, included a motivational leaflet, easily understandable information, and a questionnaire requesting to make a behavioural plan. To verify the effectiveness of the program, it was tested in the town of Tosa in Kochi Prefecture, Japan. Participants in Tosa were randomly divided into two groups, with one group serving as the control and the other as the experimental group. The results showed that understanding of sediment disaster risk was significantly higher in the experimental group than in the control group. However, the program had only a limited effect on participants who did not trust the local government, indicating the importance of the credibility of local government agencies responsible for disaster prevention. The risk-communication program also had a positive effect on inducing evacuation behaviour.

Keywords: risk communication, evacuation behaviour, psychological process model, sediment disaster.
\end{abstract}




\section{Introduction}

In Japan, warnings regarding sediment hazards have been broadcast on TV and radio since 2007 . However, it has been found that many people do not fully understand the meanings and roles of these warning notices and how they differ from other evacuation alarms or weather advisories. Furthermore, these notices do not necessarily induce evacuation behaviour [1]. An effective riskcommunication program that can induce evacuation when necessary is needed across Japan, and research on effective programs is underway. A riskcommunication program should include not only information on the risk but also tips designed to induce people to consider how they will behave in a risk situation.

One type of communicative program that has been shown to induce voluntary behavioural changes is mobility management, a "soft" transportation measure that has been adopted throughout the world [2]. Mobility management incorporates findings of psychology in a practical yet sophisticated method that can have significant effects on travel behaviour. In this study, we examined whether this practical approach from the transportation field can be applied to risk communication to induce disaster evacuation behaviour.

We developed a program to communicate sediment-disaster risk and induce evacuation behaviour. The program material included a simple motivational leaflet with information on concrete actions to take during an evacuation and a questionnaire that induced participants to consider their behavioural plan. Using control and experimental groups, we tested the program among residents of Tosa Town, Kochi Prefecture, Japan, and verified its effectiveness as a psychological process model for behavioural change.

Basically, the goal of such a communication program is to induce evacuation 'behaviour'. However, in the real world, it may be difficult to test the effectiveness of a program empirically by actual evacuation behaviour. Therefore, we tested the effectiveness of the program by measuring and analysing psychological factors that were considered to have significant relationships with behaviour.

\section{Literature review}

\subsection{Process model of risk-coping behaviour and trust}

Rowan [3] proposed the CAUSE model to describe a process of risk-coping behaviour. The model includes five phases as goals of risk communication: 'credibility', 'awareness', 'understanding', 'solution', and 'enactment'. Using this model, Fujii [4] suggested a process model to induce risk-coping behaviour.

An advantage of this model is that it is possible to determine participants' current phase of the process model and to then communicate appropriately for the phase. Moreover, this model assumes that 'credibility' is the deepest factor, reflecting many psychological research findings that 'trust' is fundamentally important in risk communication (e.g. Nakayachi and Cvetkovich [5] and 
Nakayachi and Watabe [6]). Yamagishi [7] proposed that general trust in other people or organization is determined by both trust in competency and trust in intention, and this idea has been widely accepted.

\subsection{Process model of attitude and behavioural change}

Taniguchi and Fujii [8] suggested an integrated model of voluntary change in travel behaviour. The model was based on the assumption that the behaviour of reducing car use is influenced by the behavioural intention to reduce automobile use. That behavioural intention is, in turn, influenced by psychological factors, including attitude and perceived behavioural control. These factors are considered in the theory of planned behaviour, one of the most widely used behavioural theories [9].

Behavioural intention is necessary for sustained behavioural change, but it is not sufficient. In the real world, behaviour is not always modified, even if one has an intention to do so. In an attempt to determine how intentions are implemented in behaviour, Heckhausen and Gollwitzer [10] and Gollwitzer [11, 12] distinguished between 'goal intention' and 'implementation intention'. Goal intention can be regarded as a behavioural intention [13, 14], whereas implementation intention entails a plan for when, where, and how the target behaviour is to be implemented. Gärling and Fujii [13] hypothesised that the effect of behavioural intention on behaviour is mediated by implementation intention. They used data on causal relationships among behavioural intention, implementation intention or planning, and actual behaviour to support this assumption.

\subsection{Practical measures to induce voluntary behavioural change}

Even when people have a behavioural intention, such as 'I am going to evacuate when strong rainfall occurs', they often fail to implement the actual behaviour because they lack an implementation intention. An example of an implementation intention is, 'I am going to evacuate on a specific occasion to a specific location (such as a shelter)'.

To reduce the gap between intention and behaviour and activate implementation intention, Fujii and Taniguchi [15] and Taniguchi and Fujii [16] suggested a practical technique called a 'behavioural plan' for travel-behaviour change. In their travel-behaviour plan, participants were asked to complete a questionnaire regarding a specific occasion for which they would indicate when and from where they would telephone to reserve an on-demand bus service. Their results showed that requesting participants' behavioural plans was effective in inducing voluntary change in their travel behaviour. We thought that this technique could also be applied to induce other behaviours, such as evacuation behaviour in a risk situation. 


\section{Method}

\subsection{Overview of the target area, Tosa town}

Tosa Town is located in a central, mountainous part of Shikoku Island, Japan, and receives an average of 2,500 $\mathrm{mm}$ annual rainfall. The population at the time of our study was approximately 4,500 (1,860 households). The main industries were agriculture and forestry. The population included a large percentage of people 65 years old and over, who made up $39.8 \%$ of the total population (in 2008), and in some areas, 70-80\%. Local government officials in Tosa Town were interested in implementing our experimental program and had previously cooperated in other experiments designed by national ministries and Kochi Prefecture agencies. In addition, because Tosa Town have risks of debris flow and slope failure, we used the term "sediment disaster" as a general word to express the disaster in our program.

Before implementing the program, we interviewed a town official to better understand local circumstances. The interview revealed that Tosa residents already knew of evacuation areas. However, deciding which area would be safe under specific circumstances was a problem because Tosa Town is surrounded by mountains where sediment disasters could occur. The town official hoped that residents would think about which areas would be safe and use such judgements when evacuating.

In view of these circumstances, the program had to be senior friendly, and the goal was to induce voluntary evacuation in risk situations.

\subsection{Individualised risk-communication program for a sediment disaster}

We developed a risk-communication program that included a questionnaire aimed at inducing respondents to consider their behavioural plans. Tosa Town had 46 neighbourhood associations. We excluded some, such as those that had only a single household or that did not have high potential of sediment disaster, such as areas near the river. We then chose 21 neighbourhood associations and randomly assigned them to the target group (10 associations, 819 households) and control group (11 associations, 622 households).

Figure 1 shows the experiment schedule and the surveys used to investigate the program's effectiveness. As shown in the figure, the program kit consisted of

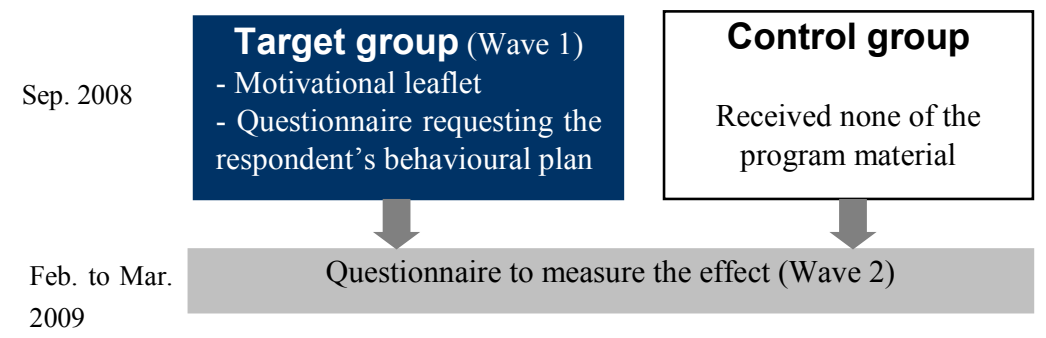

Figure 1: $\quad$ Flow diagram of the program. 
the questionnaire requesting a behavioural plan, a motivational leaflet, a sediment hazard map, and a magnet bar with which to display the behavioural plan. Kits were distributed in September 2004 to the target group through the neighbourhood associations.

All of the program kit material was designed to accommodate senior participants, such as by using large characters and having simple explanations. The program kit is described in detail below.

\section{- The questionnaire with a behavioural plan}

The one-and-a-half page questionnaire requested that participants read the motivational leaflet and refer to the hazard map for their residential area. Then, they were asked to answer questions such as the following: 'Could you mark your home on the hazard map?'; 'Is your home located within a red zone for sediment disaster?'; 'Where will you evacuate to in the case of a sediment disaster?'; 'Do you have a friend or acquaintance living within the red zone?'; 'Do you know their contact information?'

Next, respondents were asked to fill in the behavioural plan sheet. Items included 'In case of heavy rain, I will seek refuge in [location]___ '; 'The telephone number of the refuge area is [tel. number] ___ '; and 'In such cases, I will tell [person's name] ___ to seek refuge; their telephone number is

Lastly, participants were asked where they would hang the behavioural plan, such as on their refrigerator, wall, or the back of a door, and they were asked to use the magnet bar that was distributed in the program kit to do this.
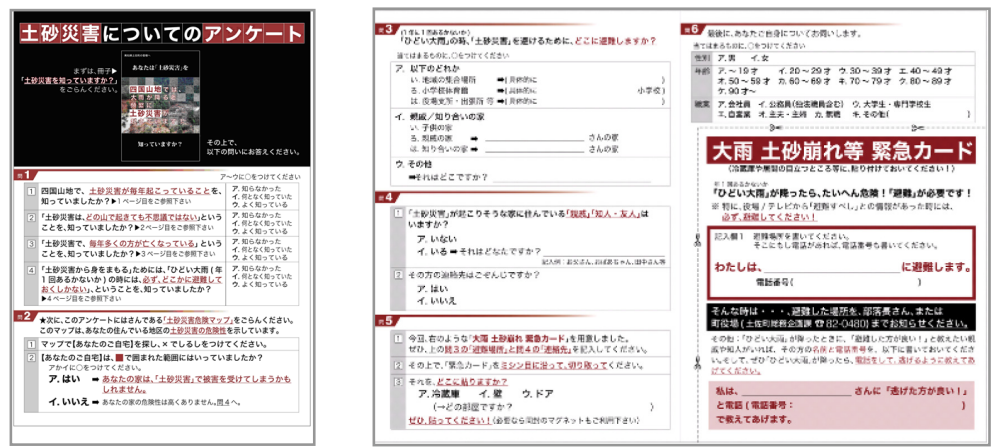

Figure 2: $\quad$ The questionnaire with behavioural plan (partial).

These questions and requests were designed to stimulate participants to consider how they would behave in the case of a sediment disaster.

\section{- The motivational leaflet}

To explain the risks of sediment disasters and how to behave appropriately, we made an A5-sized motivational leaflet. We tried to make the information as simple and easy to understand as possible. The contents of the leaflet were organised as short lists, photographs, and a graph of sediment disasters in Shikoku. The importance of evacuating to prevent human harm was emphasised. 

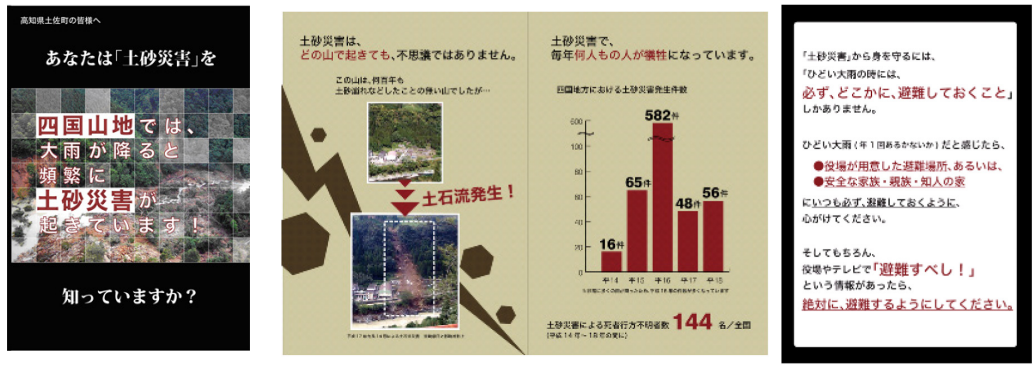

Figure 3: Motivational leaflet.

\section{- The sediment hazard map}

Using hazard data provided by Kochi Prefecture, we made four hazard maps in which sediment hazard zones were clearly indicated in red for each part of Tosa Town. The map was folded inside the questionnaire when the kit was distributed.

\section{- The magnet bar}

To remind people of sediment disaster risk and how to behave during a sediment disaster, we requested that participants place or hang the behavioural plan on their refrigerator, wall, or a door. The magnet bar was distributed to aid in displaying the plan.

About 6 months after the intervention, during February to March 2009, we distributed a questionnaire to all the households to measure the effects of the program (Wave 2).

\subsection{Framework of analysis}

As described in section 2, we used a psychological process model (Figure 3 ) to measure the effects of the risk-communication program described in subsection 3.2. This model was based on the CAUSE model, the model of trust, and the theory of planned behaviour.

The measures for each factor are shown in Table 1.

\section{Results and discussions}

We distributed the Wave 2 survey questionnaire to 1,441 households (819 target group, and 622 control group) and collected 374 (217 from the target group, 157 from the control group). We used these data to analyse the effects of the program.

\subsection{Mean, standard deviation, and $t$-test}

Table 2 shows the means and standard deviations for the target and control groups and the results of the one-tailed $t$-test assessing differences between them. Scores on all factors were higher in the target group than in the control group. A 
Table 1: Questions used to measure factors in the Wave 2 questionnaire and the possible responses to the measures.

\begin{tabular}{|c|c|c|}
\hline Index & Question & $\begin{array}{l}\text { Ends of the } \\
\text { scale/alternatives }\end{array}$ \\
\hline $\begin{array}{l}\text { Credibility } \\
\text { (general trust) }\end{array}$ & $\begin{array}{l}\text { Do you trust the local government's } \\
\text { disaster-prevention office? }\end{array}$ & $\begin{array}{l}\text { No/Yes } \\
\text { Five-point scale }\end{array}$ \\
\hline Trust in competency & $\begin{array}{l}\text { Do you think that the local government's } \\
\text { disaster-prevention office is competent to } \\
\text { prevent sediment disaster? }\end{array}$ & $\begin{array}{l}\text { No/Yes } \\
\text { Five-point scale }\end{array}$ \\
\hline Trust in intention & $\begin{array}{l}\text { Do you think that the local government's } \\
\text { disaster-prevention office intends to } \\
\text { prevent sediment disaster? }\end{array}$ & $\begin{array}{l}\text { No/Yes } \\
\text { Five-point scale }\end{array}$ \\
\hline Awareness & $\begin{array}{l}\text { Do you think that there is a risk of } \\
\text { sediment disaster in Tosa Town? }\end{array}$ & $\begin{array}{l}\mathrm{No} / \text { Yes } \\
\text { Five-point scale }\end{array}$ \\
\hline Understanding & $\begin{array}{l}\text { Do you know that many cases of } \\
\text { sediment disaster are caused by heavy } \\
\text { rain? }\end{array}$ & $\begin{array}{l}\text { No/Yes } \\
\text { Five-point scale }\end{array}$ \\
\hline Solution & $\begin{array}{l}\text { Do you think that "just evacuating" is } \\
\text { important to prevent human harm during } \\
\text { a sediment disaster? }\end{array}$ & $\begin{array}{l}\text { No/Yes } \\
\text { Five-point scale }\end{array}$ \\
\hline $\begin{array}{l}\text { Behavioural } \\
\text { intention }\end{array}$ & $\begin{array}{l}\text { Do you think that you will evacuate } \\
\text { during a heavy rain that is likely to cause } \\
\text { a sediment disaster? }\end{array}$ & $\begin{array}{l}\text { No/Yes } \\
\text { Five-point scale }\end{array}$ \\
\hline $\begin{array}{l}\text { Implementation } \\
\text { intention }\end{array}$ & $\begin{array}{l}\text { Can you imagine with whom, to where, } \\
\text { and how you will evacuate in the case of } \\
\text { heavy rain that is likely to cause a } \\
\text { sediment disaster? }\end{array}$ & $\begin{array}{l}\text { No/Yes } \\
\text { Five-point scale }\end{array}$ \\
\hline $\begin{array}{l}\dagger \text { Memory of the } \\
\text { program }\end{array}$ & $\begin{array}{l}\text { Do you remember the program held in } \\
\text { September } 2008 \text { ? }\end{array}$ & $\begin{array}{l}\text { Remember/Rememb } \\
\text { er somewhat/Do not } \\
\text { remember }\end{array}$ \\
\hline \multicolumn{3}{|c|}{$\begin{array}{l}\text { Below are dummy variables for the experimental group only based on the 'Memory of } \\
\text { the program' question. These are the dummy variables relative to the control group. }\end{array}$} \\
\hline No memory dummy & \multicolumn{2}{|c|}{$\begin{array}{l}\text { The dummy variable was set to } 1 \text { if the participant answered 'Do } \\
\text { not remember'; otherwise, the value was set to } 0 .\end{array}$} \\
\hline $\begin{array}{l}\text { Some memory } \\
\text { dummy }\end{array}$ & \multicolumn{2}{|c|}{$\begin{array}{l}\text { The dummy variable was set to } 1 \text { if the participant answered } \\
\text { 'Remember somewhat'; otherwise the value was set to } 0 .\end{array}$} \\
\hline Memory dummy & \multicolumn{2}{|c|}{$\begin{array}{l}\text { The dummy variable was set to } 1 \text { if the participant answered } \\
\text { 'Remember'; otherwise, the value was set to } 0 \text {. }\end{array}$} \\
\hline
\end{tabular}

$\dagger$ : This question was not included in the questionnaire for the control group. 


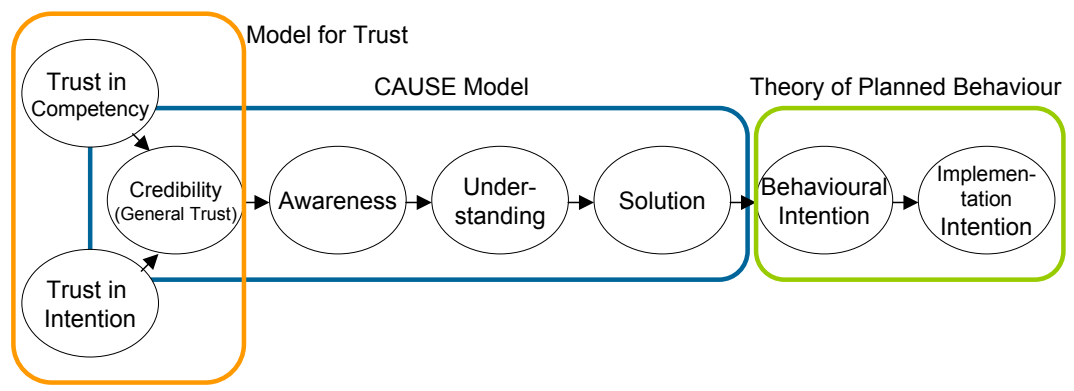

Figure 4: $\quad$ Framework of analysis based on three theories.

significant difference was found in the factor of 'understanding'. These results indicate that the risk-communication program developed in this study was effective in activating psychological factors for inducing evacuation behaviour to avoid sediment disasters.

For further analysis, the target group was divided into three groups according to answers regarding 'memory of the program'. Table 3 presents mean and standard deviations for the three groups. As shown in Table 3, more

Table 2: Comparison of the target and control groups and results of the onetailed $t$-test.

\begin{tabular}{|c|c|c|c|c|c|c|c|c|c|}
\hline & \multicolumn{3}{|c|}{ Control group } & \multicolumn{3}{|c|}{ Target group } & \multicolumn{3}{|c|}{$\begin{array}{c}t \text {-test } \\
\text { Control vs. target }\end{array}$} \\
\hline & $\mathrm{n}$ & M & SD & $\mathrm{n}$ & M & SD & $\mathrm{t}$ & $\mathrm{df}$ & $\mathrm{p}$ \\
\hline Credibility (general trust) & 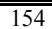 & 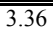 & 0.99 & 215 & 3.43 & 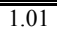 & 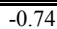 & 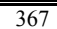 & $\overline{0.23}$ \\
\hline Trust in competency & 154 & 3.16 & 1.00 & 215 & 3.19 & 1.06 & -0.22 & 367 & 0.41 \\
\hline Trust in intention & 153 & 3.61 & 0.95 & 214 & 3.63 & 1.83 & -0.09 & 365 & 0.47 \\
\hline Awareness & 153 & 4.36 & 0.76 & 212 & 4.40 & 0.86 & -0.46 & 363 & 0.32 \\
\hline Understanding & 153 & 4.75 & 0.64 & 212 & 4.87 & 0.50 & -2.02 & 363 & 0.02 \\
\hline Solution & 154 & 4.64 & 0.64 & 216 & 4.70 & 0.64 & -0.90 & 368 & 0.18 \\
\hline Behavioral intention & 153 & 4.08 & 1.00 & 214 & 4.17 & 0.98 & -0.93 & 365 & 0.18 \\
\hline Implementation intention & 151 & 3.39 & 1.32 & 213 & 3.55 & 1.24 & -1.21 & 362 & 0.11 \\
\hline
\end{tabular}

Table 3: Mean and standard deviation of the target group categorised by memory of the program.

\begin{tabular}{|l|ccc|ccc|ccc|}
\hline & \multicolumn{3}{|c|}{$\begin{array}{c}\text { Target group, } \\
\text { no memory }\end{array}$} & \multicolumn{3}{c|}{$\begin{array}{c}\text { Target group, } \\
\text { some memory }\end{array}$} & \multicolumn{4}{c|}{$\begin{array}{c}\text { Target group, } \\
\text { memory }\end{array}$} \\
& $\mathrm{n}$ & $\mathrm{M}$ & $\mathrm{SD}$ & $\mathrm{n}$ & $\mathrm{M}$ & $\mathrm{SD}$ & $\mathrm{n}$ & $\mathrm{M}$ & $\mathrm{SD}$ \\
\hline \hline Credibility (general trust) & 43 & 2.98 & 0.89 & 67 & 3.39 & 0.98 & 86 & 3.61 & 1.00 \\
Trust in competency & 43 & 2.72 & 1.05 & 67 & 3.27 & 1.01 & 86 & 3.34 & 0.99 \\
Trust in intention & 42 & 2.95 & 1.19 & 67 & 3.88 & 2.79 & 86 & 3.66 & 1.09 \\
Awareness & 43 & 4.16 & 1.19 & 68 & 4.34 & 0.78 & 83 & 4.53 & 0.68 \\
Understanding & 41 & 4.68 & 0.91 & 66 & 4.86 & 0.46 & 86 & 4.98 & 0.15 \\
Solution & 43 & 4.56 & 0.85 & 68 & 4.60 & 0.65 & 86 & 4.86 & 0.44 \\
Behavioral intention & 43 & 3.74 & 1.29 & 68 & 4.24 & 0.88 & 84 & 4.32 & 0.87 \\
Implementation intention & 43 & 3.19 & 1.28 & 67 & 3.45 & 1.27 & 86 & 3.79 & 1.18 \\
$n$ : number in sample; M: mean; SD: standard deviation & & & & & \\
\hline
\end{tabular}


psychological factors were activated in participants who had greater memory than in those with less memory of the program. The scores in the 'no memory' group were lower than those in the control group. In the next section, we will examine the factors that led to this result.

\subsection{Psychological process model for evacuation behaviour and effects of participants' memory of the program}

To verify that the psychological process model induced evacuation behaviour and to identify which factors differed among the three groups, we used the model shown in Figure 4. In this model, the relationships between the three dummy variables (shown at the bottom of Table 1) indicating memory of the program and the psychological process model for evacuation behaviour were examined. We tested this model by using hierarchical multiple regression analysis, setting the factors on the right side as dependent variables and those on the left side as independent variables. For example, for the dependent variable 'understanding', the independent variables are 'awareness', 'credibility', 'trust in competency', 'trust in intention', and the three dummy variables.

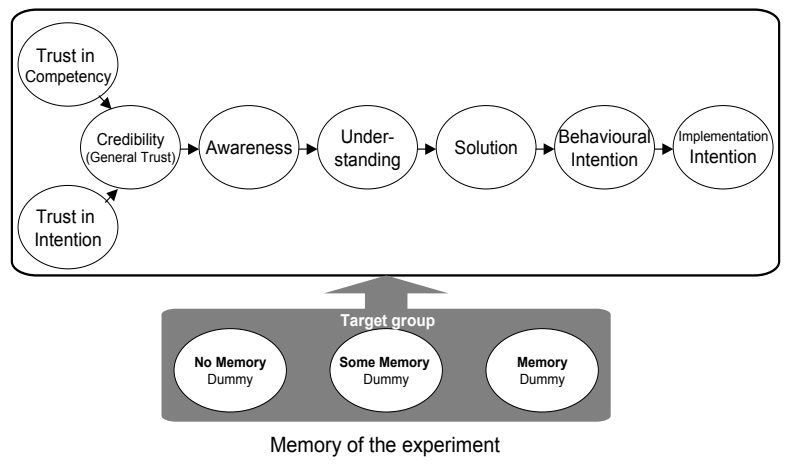

Figure 5: $\quad$ Proposed psychological process model for evacuation behaviour.

Table 4 and Figure 5 show the results of hierarchical multiple regression analysis.

First, trust in the local government's competency and trust in the local government's intention had significant effects on credibility, which replicated former research findings. Only trust in intention had a significant effect on awareness, and there was no significant effect of credibility or trust on competency. Awareness had a significant effect on understanding, and understanding and awareness had significant effects on solution. Credibility, trust in competency, and solution had significant effects on behavioural intention, and awareness had a marginally significant effect on behavioural intention. Furthermore, credibility, understanding, and behavioural intention had significant effects on implementation intention. These results indicated that the psychological process model was appropriate to describe a process of evacuation behaviour.

Additionally, trust in intention had a marginally significant negative effect on implementation intention. Although the coefficient of this pass was 
comparatively small $(=-0.08)$, further research is needed to clarify the reason for this result.

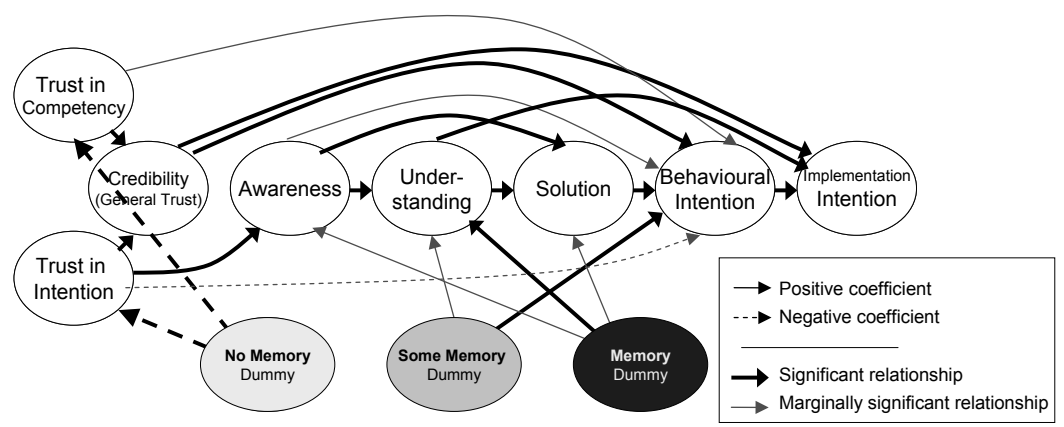

Figure 6: Results of hierarchical multiple regression analysis.

Second, concerning the dummy for memory of the program, the results shown in Figure 5 and Table 4 do not mean that there were causal relationships between the dummy variables and other psychological factors. These analyses were done to verify an existence of correlation between dummy and psychological factors and also to identify differences among the three dummy groups in comparison with the control group.

Table 4: Results of the multiple regression analyses of relationships between factors.

\begin{tabular}{|c|c|c|c|c|c|c|c|c|c|}
\hline $\begin{array}{l}\text { Dependent } \\
\text { variable }\end{array}$ & $\begin{array}{l}\text { Independent } \\
\text { variable }\end{array}$ & $\beta$ & $\mathrm{t}$ & $\mathrm{p}$ & $\begin{array}{l}\text { Dependent } \\
\text { variable }\end{array}$ & $\begin{array}{l}\text { Independent } \\
\text { variable }\end{array}$ & $\beta$ & $\mathrm{t}$ & $\mathrm{p}$ \\
\hline \multirow{11}{*}{$\begin{array}{l}\text { Implementation } \\
\text { Intention }\end{array}$} & (constant) & - & -2.15 & 0.02 & \multirow{8}{*}{ Understanding } & (constant) & - & 20.19 & 0.00 \\
\hline & Credibility (general trust) & 0.15 & 2.30 & 0.01 & & Credibility (general trust) & 0.02 & 0.31 & 0.38 \\
\hline & Trust in competency & 0.05 & 0.76 & 0.22 & & Trust in competency & -0.04 & -0.56 & 0.29 \\
\hline & Trust in intention & 0.02 & 0.32 & 0.38 & & Trust in intention & 0.04 & 0.67 & 0.25 \\
\hline & Awareness & -0.03 & -0.53 & 0.30 & & Awareness & 0.37 & 7.51 & 0.00 \\
\hline & Understanding & 0.16 & 3.01 & 0.00 & & D_No memory & -0.02 & -0.32 & 0.37 \\
\hline & Solution & 0.03 & 0.51 & 0.31 & & D_Some memory & 0.08 & 1.46 & 0.07 \\
\hline & Behavioral Intention & 0.38 & 7.08 & 0.00 & & D Memory & 0.13 & 2.47 & 0.01 \\
\hline & D_No memory & 0.02 & 0.47 & 0.32 & \multirow{7}{*}{ Awareness } & (constant) & - & 23.52 & 0.00 \\
\hline & D_Some memory & -0.05 & -0.92 & 0.18 & & Credibility (general trust) & 0.09 & 1.12 & 0.13 \\
\hline & D Memory & 0.04 & 0.80 & 0.21 & & Trust in competency & -0.07 & -0.94 & 0.17 \\
\hline \multirow{10}{*}{$\begin{array}{l}\text { Behavioral } \\
\text { Intention }\end{array}$} & (constant) & - & -0.04 & 0.48 & & Trust in intention & 0.16 & 2.83 & 0.00 \\
\hline & Credibility (general trust) & 0.13 & 1.85 & 0.03 & & D_No memory & -0.05 & -0.88 & 0.19 \\
\hline & Trust in competency & 0.10 & 1.51 & 0.07 & & D_Some memory & -0.03 & -0.55 & 0.29 \\
\hline & Trust in intention & -0.08 & -1.62 & 0.05 & & D_Memory & 0.08 & 1.35 & 0.09 \\
\hline & Awareness & 0.08 & 1.53 & 0.06 & \multirow{6}{*}{$\begin{array}{l}\text { Credibility } \\
\text { (general trust) }\end{array}$} & (constant) & - & 8.46 & 0.00 \\
\hline & Understanding & 0.02 & 0.34 & 0.37 & & Credibility (general trust) & 0.69 & 17.51 & 0.00 \\
\hline & Solution & 0.43 & 8.29 & 0.00 & & Trust in competency & 0.08 & 2.13 & 0.02 \\
\hline & D_No memory & -0.05 & -0.97 & 0.17 & & D_No memory & -0.03 & -0.86 & 0.20 \\
\hline & D_Some memory & 0.09 & 1.75 & 0.04 & & D_Some memory & -0.04 & -1.03 & 0.15 \\
\hline & D Memory & 0.01 & 0.25 & 0.40 & & D Memory & 0.04 & 0.98 & 0.16 \\
\hline \multirow{9}{*}{ Solution } & (constant) & - & 7.11 & 0.00 & \multirow{4}{*}{$\begin{array}{l}\text { Trust } \\
\text { in competency }\end{array}$} & (constant) & - & 40.73 & 0.00 \\
\hline & Credibility (general trust) & 0.07 & 0.95 & 0.17 & & D_No memory & -0.14 & -2.59 & 0.00 \\
\hline & Trust in competency & -0.01 & -0.18 & 0.43 & & D_Some memory & 0.04 & 0.65 & 0.26 \\
\hline & Trust in intention & 0.03 & 0.54 & 0.29 & & D Memory & 0.07 & 1.21 & 0.11 \\
\hline & Awareness & 0.11 & 2.13 & 0.02 & \multirow{4}{*}{$\begin{array}{l}\text { Trust } \\
\text { in intention }\end{array}$} & (constant) & - & 31.83 & 0.00 \\
\hline & Understanding & 0.38 & 7.27 & 0.00 & & D_No memory & -0.15 & -2.75 & 0.00 \\
\hline & D_No memory & -0.02 & -0.31 & 0.38 & & D_Some memory & 0.05 & 0.97 & 0.17 \\
\hline & D_Some memory & -0.05 & -0.91 & 0.18 & & D_Memory & 0.00 & -0.06 & 0.48 \\
\hline & D Memory & 0.07 & 1.35 & 0.09 & \multicolumn{5}{|c|}{$\beta:$ Standardized coefficient; $p$ : significance (one-tailed) } \\
\hline
\end{tabular}


As shown in Figure 5 and Table 4, the 'no memory' dummy had a significant negative relationship with trust in competency and trust in intention. The reason for this result is uncertain, but a possible explanation may be that people who did not trust local government did not put serious effort into the program and thus did not remember the program. The 'some memory' dummy was significantly associated with behavioural intention and had a marginally significant relationship with understanding. The 'memory' dummy showed a significant association with understanding and a marginally significant association with awareness and solution. There results suggest that the more people were aware of the risk of sediment disaster, the more memory they had of the program.

Overall, our results indicate that our psychological process model was appropriate for describing the process of evacuation behaviour. Furthermore, trust in local government was found to be a fundamental factor in inducing voluntary evacuation behaviour. If people did not trust in local government for disaster prevention, they tended not to remember the risk-communication program provided by the local government.

\section{Conclusion}

We developed an individualised risk-communication program to induce voluntary evacuation behaviour as a governmental measure and tested the program in Tosa Town in Kochi Prefecture, Japan. We then examined the psychological variables that were directly associated with evacuation behaviour and created a psychological process model based on existing theories.

Our results showed that scores on psychological factors supporting an evacuation plan were significantly higher for the target group than the control group. The psychological process model that we suggested was also found to be appropriate for describing a process of evacuation behaviour. Furthermore, trust in local government was of fundamental importance in inducing voluntary evacuation behaviour.

In this program, psychological factors such as understanding and behavioural intention were activated in at least $70 \%$ of the target group (the total of the memory and some memory groups). Additionally, nearly $30 \%$ of the target group reported that they displayed their behavioural plan in their home (e.g., on a wall, the refrigerator, or a door). These results suggest that the program was effective and practical. Future research should examine the applicability of this program to government measures in other areas.

\section{Acknowledgements}

The English in this document has been checked by at least two professional editors, both native speakers of English. For a certificate, please see: http://www.textcheck.com/certificate/fRIfY1. 


\section{References}

[1] Japanese Meteorological Agency (2010) Report of the results concerning utilization of weather and disaster information, http:/www.jma.go.jp /jma/kishou/hyouka/manzokudo/22manzokudo/22manzokudo_kekka.pdf (in Japanese), p. 34.

[2] European Platform on Mobility Management (EPOMM) WEB site: http://www.epomm.eu/

[3] Rowan, K. E. (1994) Why rules for risk communication are not enough: A problem-solving approach to risk communication. Risk Analysis 14, pp. 365-374.

[4] Fujii, S. (2007) Risk recognition and communication, earthquakes and human beings, chapter 3, Ohno, R., Fujii, S., Aoki, Y., Osaragi, J., Seo, K., (eds.), Urban Earthquake Engineering Series, Asakura syoten (in Japanese).

[5] Nakayachi, K. and Cvetkovich, G. (2010) Public trust in government concerning tobacco control in Japan. Risk Analysis, 30(1), 143-152.

[6] Nakayachi, K. and Watabe, M. (2005) Restoring trustworthiness after adverse events: The signaling effects of voluntary "Hostage Posting" on trust. Organizational Behavior and Human Decision Processes, 97(1), 1-17.

[7] Yamagishi, T. (2011) Trust - the evolutionary game of mind and society (The science of the mind), Springer.

[8] Taniguchi, A. and Fujii, S. (2007) Process model of voluntary behavior modification and effects of travel feedback programs, Transportation Research Record, 2010, pp. 45-52.

[9] Conner, M., and Armitage, C.J. (1998) Extending the theory of planned behavior: A review and avenues for further research. Journal of Applied Social Psychology, 28, 1429-1464.

[10] Heckhausen, H., and Gollwitzer, P.M. (1987) Thought contents and cognitive functioning in motivational versus volitional states of mind. Motivation and Emotion, 11, 101-120.

[11] Gollwitzer, P. M. (1993) Goal achievement: The role of intentions. European Review of Social Psychology, 4, 141-185.

[12] Gollwitzer, P. M. (1996) The volitional benefits of planning. In P. M. Gollwitzer and J. A. Bargh (Eds), The psychology of action: Linking cognition and motivation to behavior (pp. 287-312). New York: Guilford Press.

[13] Gärling, T., and Fujii, S. (2002) Structural equation modeling of determinants of planning. Scandinavian Journal of Psychology, 43(1), 1-8.

[14] Fujii, S. (2005) Reducing inappropriate bicycle-parking through persuasive communication, Journal of Applied Social Psychology, 35(6), 1171-1196.

[15] Fujii, S., and Taniguchi, A. (2005) Reducing family car use by providing travel advice or requesting behavioral plans: An experimental analysis of travel feedback programs, Transportation Research D, 10(5), 385-393.

[16] Taniguchi, A. and Fujii, S. (2007) Promoting public transport using marketing techniques in mobility management and verifying their quantitative effects, Transportation, 34(1) 37-49. 